\title{
Allelic loss OF SELECTED TUMOR SUPPRESSOR GENES IN ACUTE LYMPHOBLASTIC LEUKEMIA IN CHILDREN
}

\author{
Ewa Studniak ${ }^{1}$, Eliza Maloney ${ }^{2}$, Tomasz Ociepa ${ }^{2}$, Tomasz Urasiński², Katarzyna SkonieczKa ${ }^{3}$, \\ Olga Haus $^{3}$, Anna Poluha ${ }^{4}$, Jerzy KowalczyK ${ }^{4}$, StanisŁaw ZajaczeK ${ }^{1}$
}

\begin{abstract}
${ }^{1}$ Cytogenetic Unit, Department of Pathology, Pomeranian Medical University, Szczecin, Poland 2Department of Paediatrics, Haematology and Oncology, Pomeranian Medical University, Szczecin, Poland 3Department of Clinical Genetics, Collegium Medicum, Nicolaus Copernicus University, Bydgoszcz, Poland 4Department of Paediatrics Haematology, Oncology and Transplantology, Medical University, Lublin, Poland
\end{abstract}

\begin{abstract}
Defect in function of tumor suppressor genes may lead to initiation/progression of leukemias. RB1, CDKN2A and TP53 gene alterations are found in acute lymphoblastic leukemia (ALL) in children. Data showing a contribution of these alterations to the pathomechanism of leukemias are contradictory and their impact on a disease course still remains undefined. The main aim of the study was to identify and the characterize of RB1, CDKN2A and TP53 allele loss in ALL children patients at diagnosis. 46 children with de novo ALL were examined. Fluorescent in situ hybridization was performed on bone marrow smear preparations. We demonstrated that at least one of three investigated deletions occurred statistically more frequently in T-lineage leukemia patients $(\mathrm{p}=0.044)$; this was the most frequent in respect to $R B 1$ gene $(p=0.054)$. Additionally, at least one of the examined deletions was observed statistically more frequently in patients with WBC above $20000 / \mu \mathrm{l}(\mathrm{p}=0.043)$, this was the most frequent for CDKN2A gene $(\mathrm{p}=0.066)$. Presented results seem to give an evidence that deletions of RB1 and CDKN2A genes may contribute to the development of hyperleukocytic type of T-lineage ALL in children, nevertheless this observation needs further investigations.
\end{abstract}

Key words: RB1, CDKN2A, TP53, ALL, FISH, mono- and bi-allelic loss.

\section{Introduction}

$R B 1, C D K N 2 A$ and TP53 gene products play a direct role in cell proliferation control, cell cycle regulation and repair of DNA damage: CDKN2A protein regulates $R B 1$ and TP53 pathways, which influence apoptosis directly as well as through cell cycle regulation. Defect in function of suppressor genes deregulates cell growth $[1,2]$. RB1, CDKN2A and TP53 gene alterations such as translocations, deletions, amplifications or point mutations occur in acute leukemias in children; however, the data that refer to the contribution of these alterations to the pathomechanism of leukemias are repeatedly discrepant and ambiguous, and their impact on the disease course still remains undefined.
$R B 1$ gene deletions as well as their possible effect on the course of a disease have been described in certain leukemias [3-5]. Similarly, coexistence with other high-risk markers was suggested $[6,7]$. TP53 gene alterations have also been observed in a variable percentage of acute lymphoblastic leukemia (ALL) patients. Deletions in the CDKN2A gene occur in leukemias in a significant percentage of patients particularly but not only in T-lineage ALL [8-12]. A possible association of these deletions with poor prognosis and minimal residual disease (MRD) was suggested [7, 13, 14]. Detection of minimal residual disease could not be included in this study and requires different investigations.

The data describing alterations in the number of RB1, CDKN2A and TP53 alleles in ALL cells are high- 
ly inconsistent. We have made an effort to describe the prevalence and the significance of $R B 1, C D K N 2 A$ and TP53 allele loss in childhood ALL and its correlation with certain subforms of the disease.

\section{Material and methods}

The study group comprised 46 pediatric patients (19 girls and 27 boys aged 8-243 months: mean 98.89 months, median: 90.5 months) with de novo ALL diagnosed between 2006 and 2010. Two patients aged 239 and 243 months were included in the study group because of their hospitalization in the Pediatric Department. B-lineage ALL was diagnosed in 35 patients, T-lineage ALL in 11. Bone marrow specimens were obtained in the course of routine diagnostic procedures. We performed fluorescence in situ hybridization (FISH) analyses on bone marrow smear preparations obtained from patients prior to the treatment. Bone marrow smears were air dried at room temperature for $1 \mathrm{~h}$, then fixed in freshly prepared acetic acid and methanol (1 : 3) fixative solution for $20 \mathrm{~min}$, and stored at $-18 æ \mathrm{C}$. All FISH probes were provided by $V y$ sis; FISH procedure was performed according to the manufacturer's routine protocol. LSI 13 (RB1) 13 q14 Spectrum Orange Probe was used for the RB1 gene, LSI $p 16$ (9p21) Spectrum Orange/CEP 9 Spectrum Green Probe for the CDKN2A gene and LSI TP53 Spectrum Orange Probe for the TP53 gene. Bone marrow smears were analyzed with a fluorescent microscope, concerning each probe, 200 consecutive cells matching the legibility criteria were evaluated. The clinical and laboratory characteristics of patients as well as results of FISH analysis are presented in Table I. The method error for each probe was determined on peripheral blood smears of healthy donors. There were 300 interphase nuclei evaluated per probe. The threshold of error for the cells bearing a deletion was estimated at the level of $0.55 \%$ for the $R B 1$ probe, $0.66 \%$ for the CDKN2A probe and $0.33 \%$ for the TP53 probe.

In order to test the statistical correlation between discontinuous variables $\chi^{2}$ Pearson's test was applied. $\mathrm{P}$ values $<0.05$ were considered statistically significant.

\section{Results}

The results of the FISH analysis of $R B 1, C D K N 2 A$ and TP53 genes are presented in Fig. 1 and the percentage of cells with deletion is presented in Fig. 2.

\section{$R B 1$ gene}

Monoallelic deletions of the $R B 1$ gene were observed in 11/46 (24\%) patients: 6 with B-lineage ALL, 5 with T-lineage ALL. The percentage of cells with the monoallelic deletion was $2 \%-70 \%$ (mean $36 \%$, median $3 \%$ ). Biallelic deletions of RB1 were not found. An ex- ample of any possible results of the $R B 1$ gene is presented in Fig. 2.

\section{$C D K N 2 A$ gene}

Deletions of the CDKN2A gene were observed in $13 / 46$ (28\%) patients: 8 with B-lineage ALL, 5 with T-lineage ALL. The percentage of cells with a deletion was $2 \%-84 \%$ (mean $43 \%$, median $40 \%$ ). Only in the CDKN2A gene, biallelic deletions were observed in 4 patients ( 1 with B-lineage ALL, 3 with T-lineage ALL). An example of results of the $C D K N 2 A$ gene FISH analysis is presented in Fig. 3.

\section{TP53 gene}

Monoallelic deletions of TP53 were found in 5/46 (11\%) patients: 3 with B-lineage ALL, 2 with T-lineage ALL. The percentage of cells with the deletion was 2$20 \%$ (mean $11 \%$, median 3\%). TP53 was the only analyzed gene which showed increased $(15-70 \%$, mean $42.5 \%$ ) numbers of copies in $7 / 46(15 \%)$ patients (6 with B-lineage ALL, 1 with T-lineage ALL). Results of the TP53 gene FISH analysis are presented in Fig. 4.

Concomitant deletions (presented in Fig. 5) of RB1 and $C D K N 2 A$ gene copies were seen in 8/46 patients (17\%): CDKN2A and TP53 genes in 4/46 patients (9\%) and RB1 and TP53 deletions in 2/46 patients (4\%). Deletions of all three genes, i.e. simultaneous allele loss of $R B 1, C D K N 2 A$ and TP53, were found in 2/46 patients $(4 \%)$.

Statistical analysis demonstrated that deletions of the $R B 1$ gene were more frequent in T-lineage ALL than in B-lineage ALL patients $(\mathrm{p}=0.054)$; likewise, coexistence of the RB1 and P16 gene deletions occurred significantly more often in patients with T-lineage ALL $(\mathrm{p}=0.044)$. CDKN2A gene deletion alone $(\mathrm{p}=$ 0.066 ), as well as the coexistence of $R B 1, C D K N 2 A$ and TP53 deletions, was more frequently observed in patients with WBC (white blood count) above $20000 / \mu \mathrm{l}(\mathrm{p}=0.043)$.

\section{Discussion}

Deletions of the RB1 gene were observed in $24 \%$ of children. According to various authors these alterations are present in 2-38\% of patients [15-17]. Discrepancies in findings of different authors may result from various methods employed, distinct leukemia types and differences in ethnicity of studied patients $[4,5$, $18,19]$. The percentage of cells showing deletions has not been evaluated in individual ALL patients. The only published study concerned CLL patients, where a high percentage of cells with the deletion correlated with poor prognosis [20].

The phenomenon of allele loss was observed only in $\sim 1 / 4$ of patients, so it may be assumed that it is not involved in the etiology and pathomechanism of the 


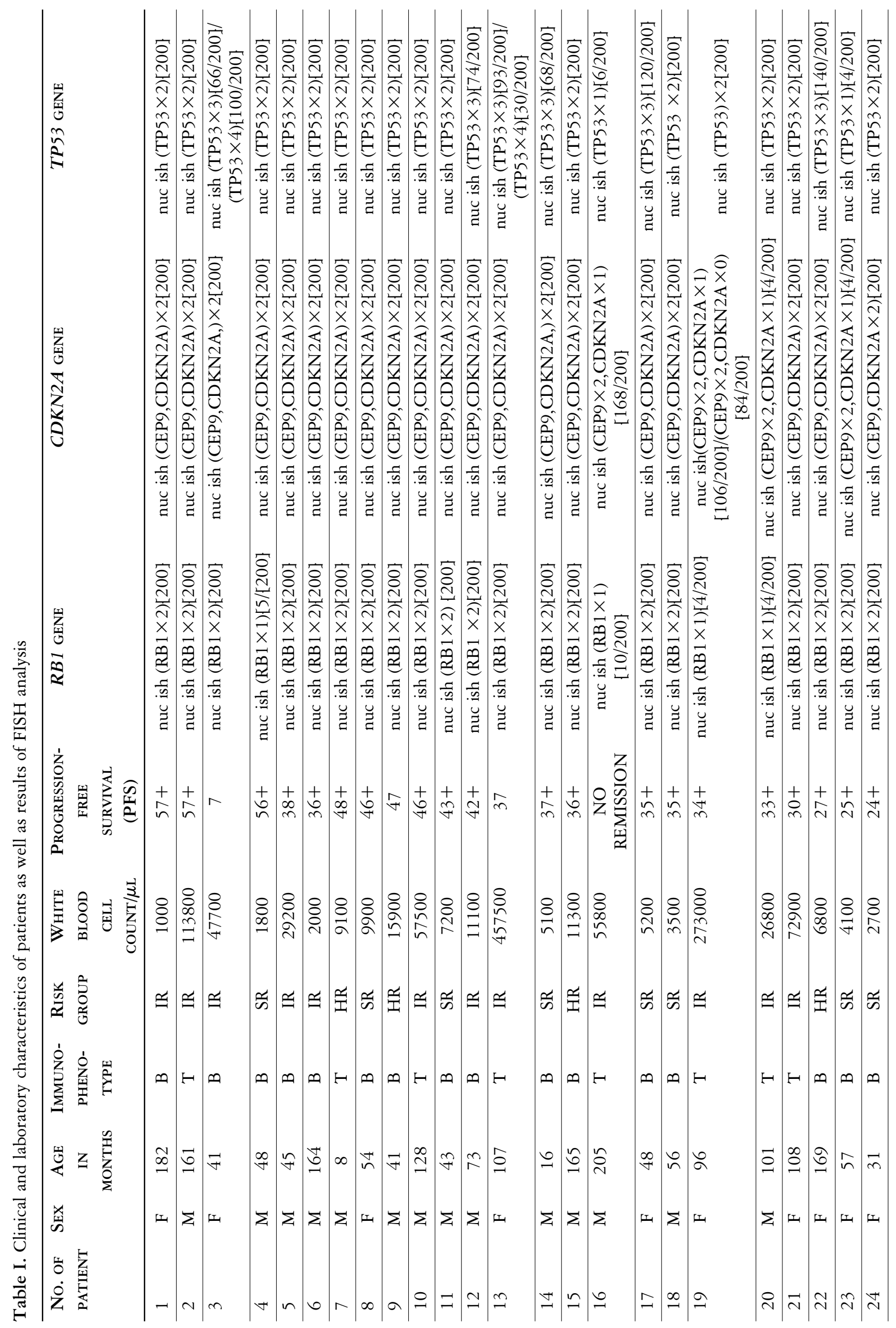




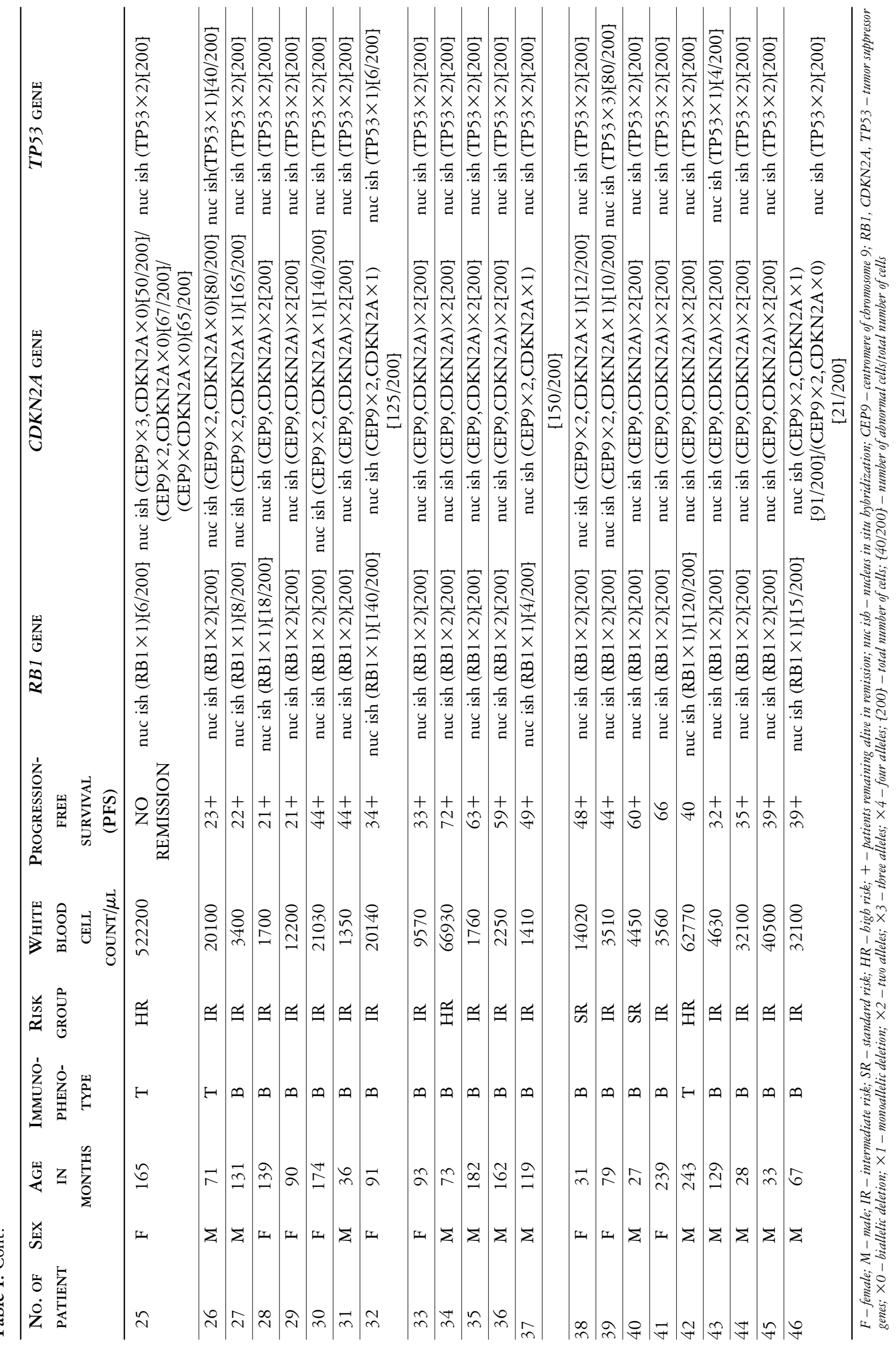




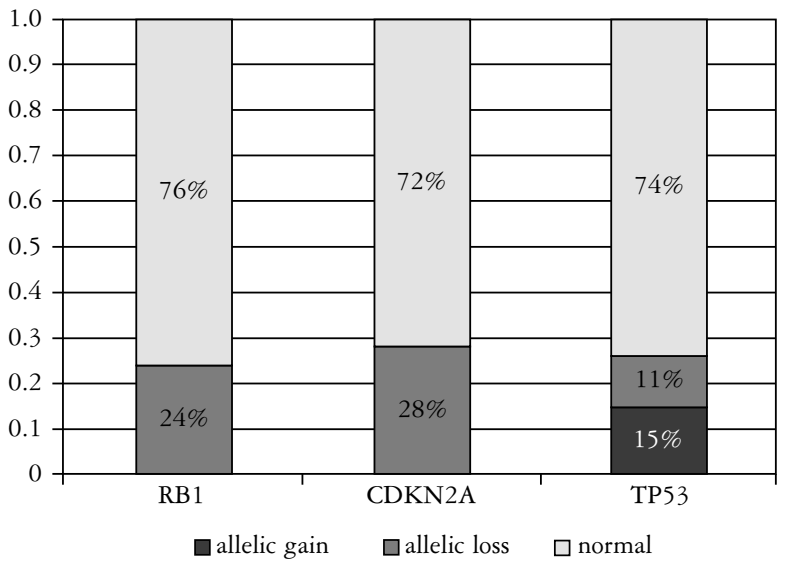

Fig. 1. Results of FISH analysis of RB1, CDKN2A and TP53 genes (number of patients)

disease, but it may rather influence the clinical course of leukemia and its prognosis. A possible interpretation of such a mechanism is an impact of $R B 1$ gene activity on the level of expression of other genes which contribute to regulation of apoptosis and cell proliferation. In the study of Hernandez et al., patients with a high percentage of cells bearing the deletion showed overexpression of genes related to proliferation $(M A P K$, $G R B S, R A S, S O S 1)$ and decreased expression of genes which block the cell cycle $(C D K N 2 C, Z A K$, genes of the $G A S$ group); low expression of the latter genes led to increased cell proliferation as well. In contrast, in patients with $R B 1$ deletion, genes which enhance apoptosis (CASP6, CLU, E2F1) showed decreased expression, causing a reduction in apoptosis rate and more aggressive clinical course of the disease [20].

Some authors suppose that biallelic deletion of the $R B 1$ gene is accompanied by loss of protein activity manifested by complete loss of its expression. Thus,

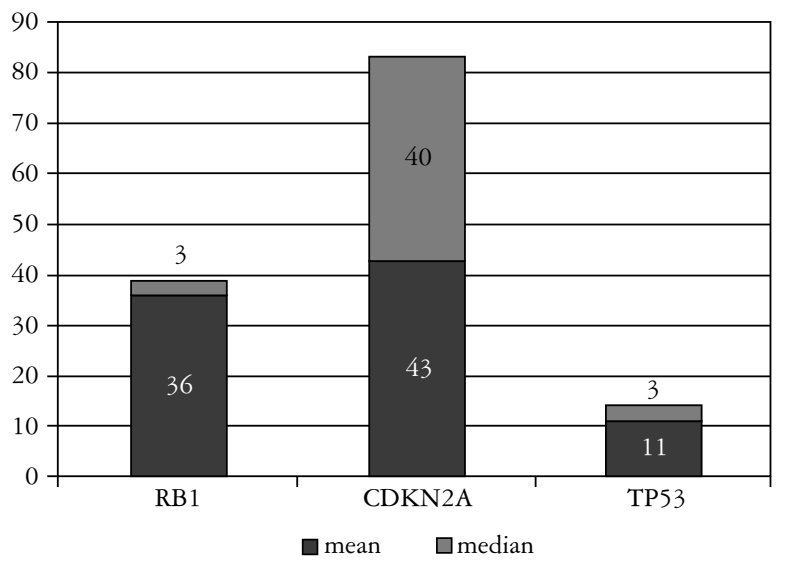

Fig. 2. Percentage (mean and median) of cells with deletion of RB1, CDKN2 and TP53 genes

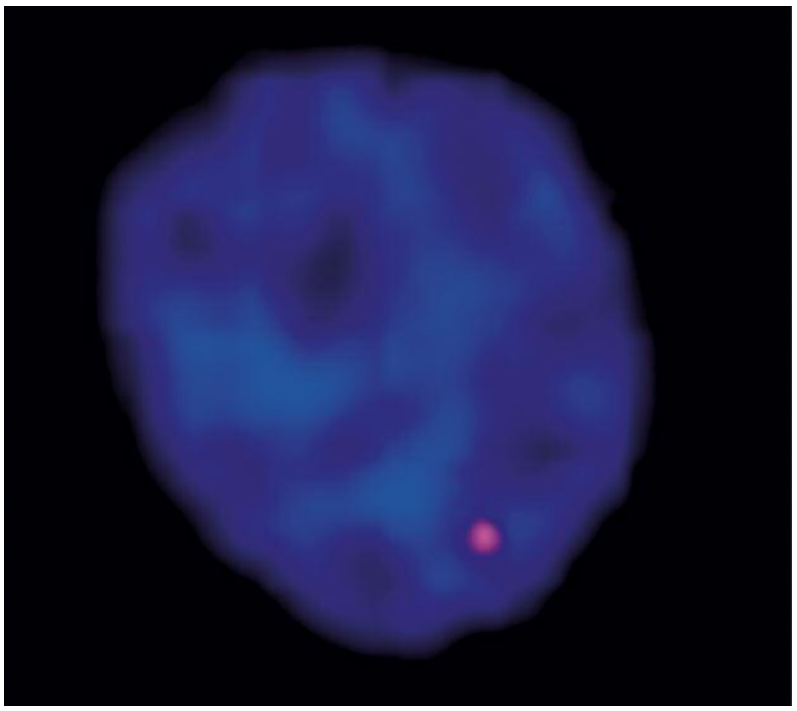

Fig. 3. Results of FISH study using Vysis LSI RB1 probe: one red signal (monoallelic deletion)
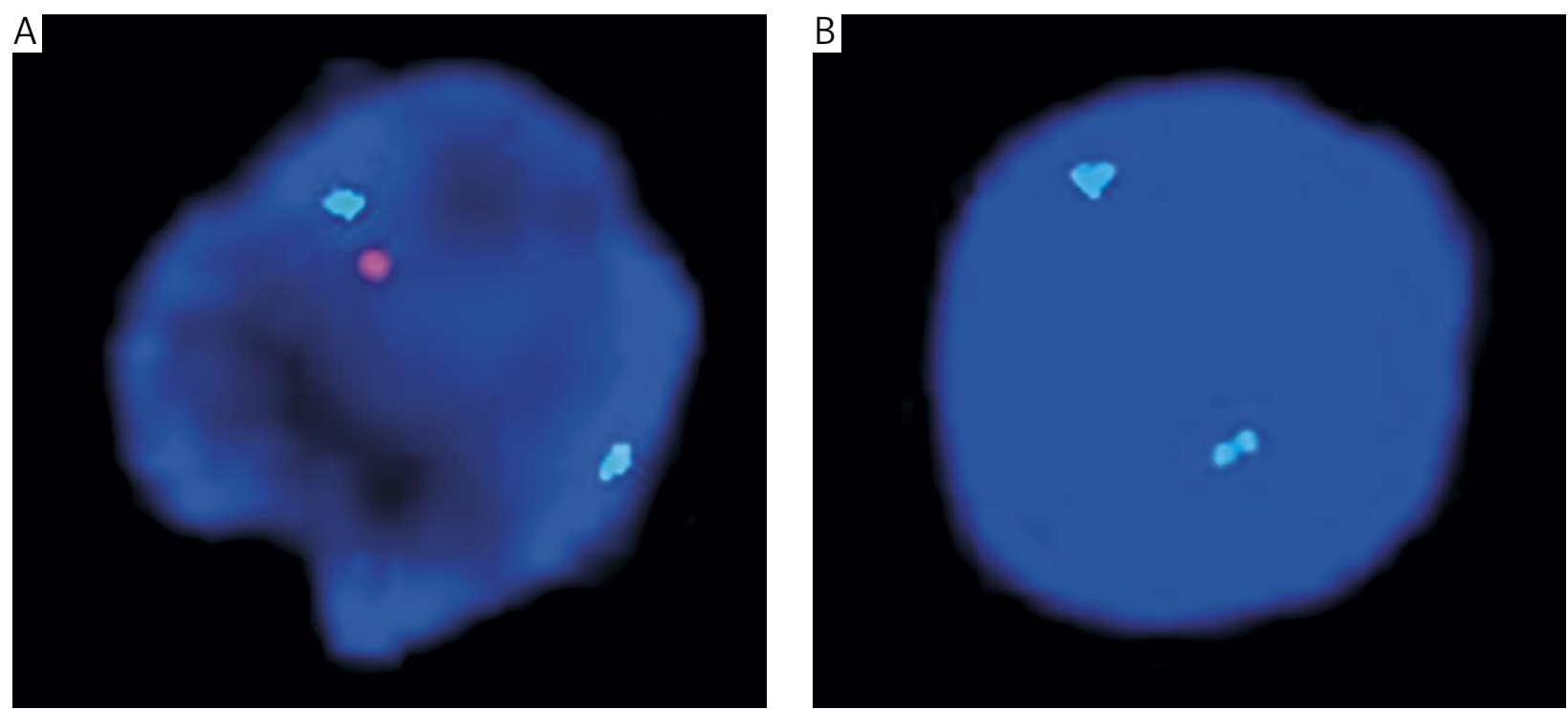

Fig. 4. Results of FISH study using Vysis LSI CDKN2A/P16 probe: A - two green control signals and one red signal (monoallelic deletion) $\mathbf{B}$ - two control green signals and no red signals (biallelic deletion) 

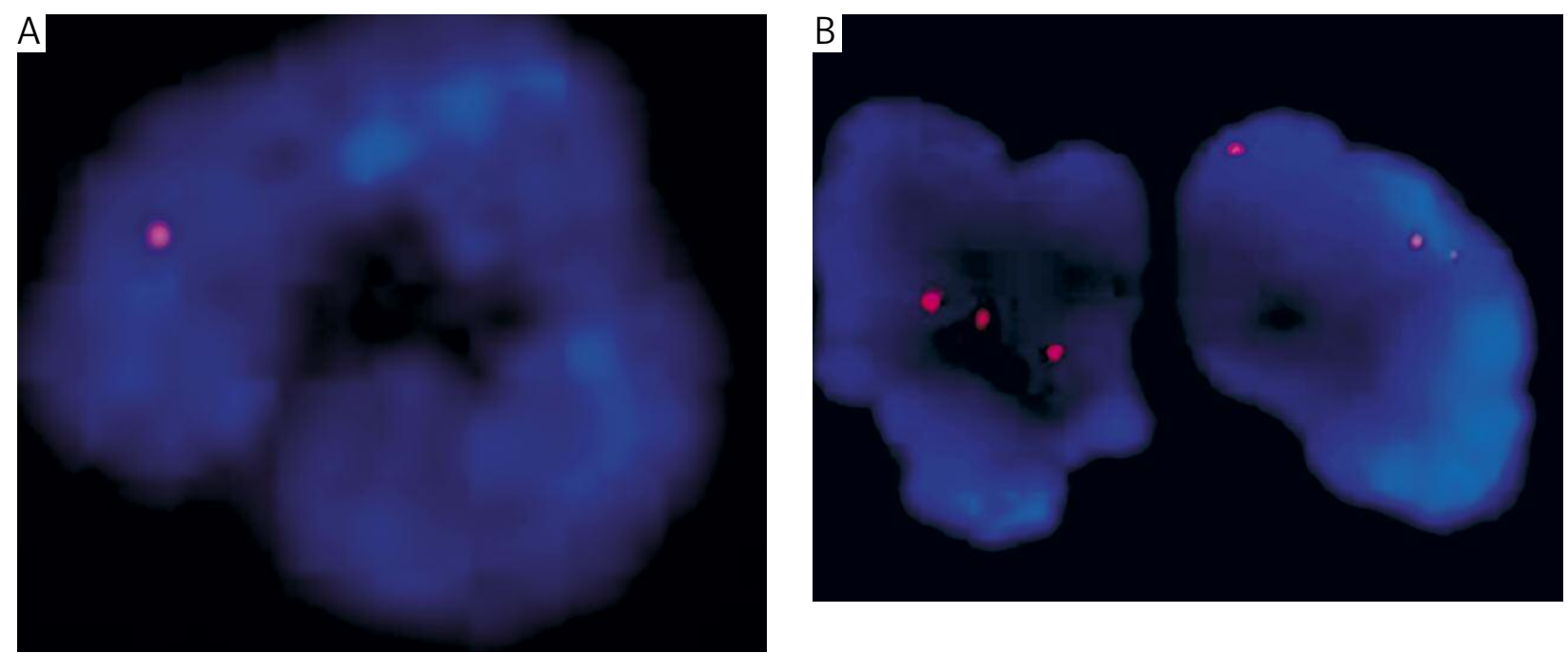

Fig. 5. Results of FISH study using Vysis LSI TP53 probe: A - one red signal (monoallelic deletion). B - three red signals

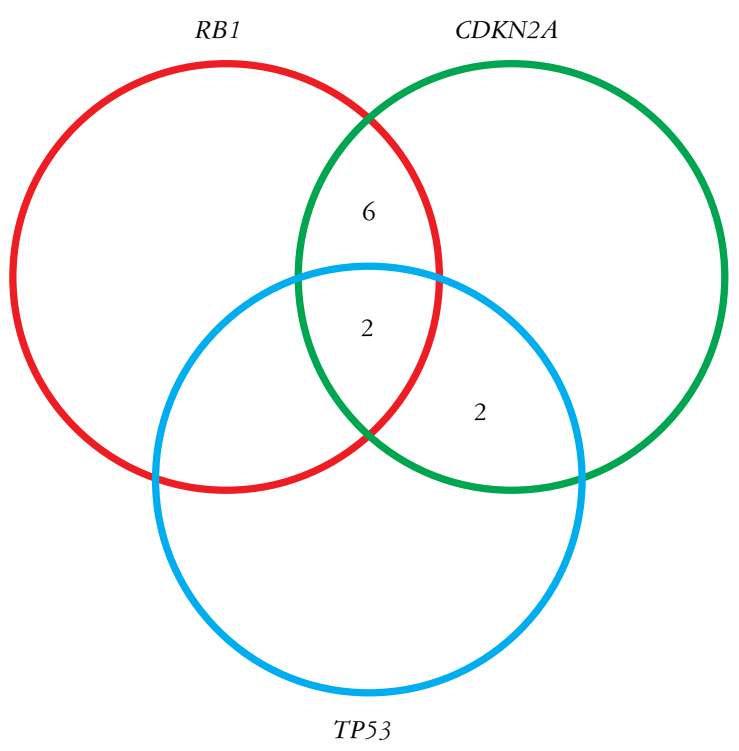

Fig. 6. Number of patients with concomitant deletions of RB1 and CDKN2A genes (8/46), CDKN2A and TP53 genes (4/46 patients), RB1 and TP53 (2/46) and deletions of all three genes $(2 / 46)$

a question arises whether decreased gene expression may result from the loss of one allele or, as in retinoblastoma, it has to be a consequence of the loss of both alleles. One of the activity loss mechanisms might be point mutation of the second allele, which is usually undetectable by FISH. In the mechanism of retinoblastoma development, gross deletion, detectable by FISH, usually appears as the second, subsequent somatic mutation, which might be in line with our findings. In the study published by Cheng et al. RB1 gene expression alterations were found in $18 \%$ of patients with different types of ALL [21]. One way to measure the expression of $\mathrm{RB} 1$ protein is the level of its phosphorylation. It was shown that the level of RB1 phosphorylation in patients with B-cell ALL is higher prior to the treatment and is declining in response to glucocorticosteroids [22].

Most studies showing loss of $R B 1$ alleles in leukemic cells have comprised patients with the B-lineage case since it is the predominant form of ALL; however, it was suggested that the alterations in genes which control G1/S phase, such as the RB1 gene, play an important role only in differentiation of $B$-lineage but not of $\mathrm{T}$-lineage leukemias. Rearrangements of the $R B 1$ gene in pre-B ALL were found in $38 \%$ of pediatric patients [23]. Other authors have also found RB1 gene deletion exclusively in B-ALL, in $16 \%$ of children and $11 \%$ of adults, respectively $[17,18]$. Our findings did not support this observation because $R B 1$ gene deletions were present in both T and B-lineage ALL. This is in line with the study of Paulsson's group, who found $R B 1$ deletion also in T cell leukemia [24].

$C D K N 2 A$ allele loss was observed in $28 \%$ of patients. In the available literature there is a wide percentage range of children or adult ALL patients bearing these alterations: $8 \%$ up to $95 \%[25,26]$. The various percentages of patients with loss of the $C D K N 2 A$ allele may result from different age of patients. CDKN2A deletions were also detected using different technique: $~ 8-44 \%$ of patients (Southern blot), 17-53\% (RT-PCR) and in $31-73 \%$ of patients (Q-PCR) [10, 16, 27-29].

In our study monoallelic deletions of the CDKN2A gene were observed both in B-lineage and T-lineage ALL patients with the predominance of T-ALL patients, which corresponds to the results of other authors [9, 29]. In the observations of Carter $e t$ al., proportions of B-lineage and T-lineage ALL patients with CDKN2A deletions were equal [30]. One possible reason for such divergence might be the fact that these analyses were done employing different methods and in patients at different age.

$C D K N 2 A$ is the only one among analyzed genes which also showed biallelic deletions; however, they were found less frequently as compared to monoallel- 
ic deletions. Some authors observed both deletion types in an equal percentage of patients $[8,9]$. Others found biallelic deletions in a higher number of patients than the monoallelic ones and some authors found biallelic deletions in a lower number of patients $[7,27,30$, 31]. Conversion of monoallelic into biallelic deletion requires additional time; therefore biallelic deletions might be more likely in adults.

In our study biallelic deletions were rather uncommon; however, they were found in 4 out of 11 (27\%) patients with T-lineage ALL. It is in line with the findings of Drexler et al.: biallelic deletions were observed more often in T-lineage ALL (64\%) [32]. It is interesting that, for unknown reasons, in our results, $8 / 13$ patients (61\%) with $C D K N 2 A$ allelic loss presented with WBC over $200000 / \mu l$.

It is supposed by the majority of authors that $C D K N 2 A$ deletions are among possible factors of poor prognosis $[11,28,32,33]$. However, other reports indicate that this is not a distinct prognostic marker and a poor prognosis results rather from coexistence of other factors [6, 10, 33-35]. Nevertheless, worse prognosis is more often related to the presence of biallelic deletion and a complete lack of CDKN2A protein expression rather than to the presence of monoallelic deletion coexisting independently of mentioned cytogenetic factors. According to the literature, duration of remission was considerably shorter in the group of patients with deletions in comparison to the group of patients without the deletion. Patients with CDKN2A deletions also showed notably higher risk of relapse $[28,35]$. Kim et al. speculate that the presence of biallelic deletion has a negative impact on the overall survival time in adults but not in children [7]. Our observations differ from those of Kim et al., since their results were obtained in studies on B-ALL patients, whereas in our study the majority of patients with biallelic deletions had prognostically worse T-lineage ALL. It might be stated that the prognostic relevance of $C D K N 2 A$ gene deletions in children with ALL cannot be defined as yet; however, existing data suggest an impact of CDKN2A deletions on prognosis in childhood ALL.

Monoallelic deletions of the TP53 gene were found in $11 \%$ of patients; thus they do not seem to be, like $R B 1$ and $C D K N 2 A$ deletions, a factor initiating ALL. Using FISH, Aqirre et al. detected TP53 deletions in $7 \%$ of patients with ALL [36]. This is in line with our results confirming a much lower incidence of TP53 deletions as compared with those of $R B 1$ or $C D K N 2 A$. The low percentage of cells with TP53 deletion in ALL patients as well as the resistance of ALL cells to apoptosis reported in the literature suggests that apoptosis in ALL might also be regulated by mechanisms disturbing TP53 gene function other than these deletions [37].

In our study, TP53 deletion was found in 3/35 (9\%) patients with B-lineage ALL and in 2/11 (18\%) patients with T-ALL. To our best knowledge, data on the fre- quency of TP53 deletion in children with ALL have not been reported. The only available data on this issue indicate that the frequency of point mutations in children with B- and T lineage ALL varies from 2 to $5 \%$ and from 5 to $50 \%$ respectively [12].

The mean number of cells with loss of the TP53 allele was the lowest in comparison to other analyzed genes (11\%). According to our best knowledge the rate of cells showing TP53 deletions in patients with ALL has not been evaluated. Lazaridou et al. observed loss of one allele of the TP53 gene in $29 \%$ of CLL patients with 28$98 \%$ of cells bearing this deletion. Alterations of TP53 occurred in the majority of patients at clinical presentation [38]. The deletions of both alleles of the TP53 gene were not found in our patients, but it does not exclude the possibility of the loss of function of both alleles. It may be analogous to the loss of heterozygosity ( $\mathrm{LOH})$, i.e. coexistence of both deletion of one allele and point mutation of the homologous one. This phenomenon was described by Wattel et al., who detected $17 \mathrm{p}$ deletion coexisting with missense mutation of the second TP53 copy in half of ALL patients, while the point mutation alone was found in remaining cases [39]. These observations seem to indicate that coexistence of deletion and point mutation of TP53 may have a different functional impact than the gene deletion alone [40].

\section{Conclusions}

1. RB1, CDKN2A and TP53 gene deletions are found in substantial proportions of children with ALL, occurring with a various frequency.

2. The results of our study seem to indicate that deletions of $R B 1$ and $C D K N 2 A$ cancer suppressor genes may contribute to the development of hyperleukocyte types of T-lineage ALL in children; nevertheless, this observation as well as assessment of its prognostic significance needs further investigation.

The authors declare no conflict of interest.

\section{References}

1. Weinberg RA. Tumor suppressor genes. Science 1991; 254 : 1138-1146.

2. Kohno T, Yamada Y, Tawara M, et al. Inactivation of p14ARF as a key event for the progression of adult T cell leukemia/lymphoma. Leuk Res 2007; 31: 1625-1632.

3. DiCiommo D, Gallie BL, Bremner R. Retinoblastoma: the disease, gene and protein provide critical leads to understand cancer. Cancer Biology 2000; 10: 255-269.

4. Cave H, Avet-Loiseau H, Devaux I, et al. Deletion of chromosomal region 13 q14.3 in childhood acute lymphoblastic leukemia. Leukemia 2001; 15: 371-376.

5. Kovacs BZ, Niggli FK, Betts DR. Aberrations involving 13 q12-q14 are frequent secondary events in childhood acute lymphoblastic leukemia. Cancer Genet Cytogenet 2004; 151 : 157-161. 
6. Mirebeau D, Acquaviva C, Suciu S, et al. The prognostic significance of CDKN2A, CDKN2B and MTAP inactivation in B-lineage acute lymphoblastic leukemia of childhood. Result of the EORTC studies 58881 and 58951. Hematol J 2006; 91: 881-885.

7. Tutor O, Diaz M, Ramirez MA, et al. Loss of heterozygosity of p16 correlates with minimal residual disease at the end of the induction therapy in non-high risk childhood B-cell precursor acute lymphoblastic leukemia. Leukemia Res 2002; 26: 817-820.

8. Moorman AV, Harrison J, Buck G, et al. Karyotype is independent prognostic factor in adult acute lymphoblastic leukemia (ALL): analysis of cytogenetic data from treated on the Medical Research Council (MRC) OKALLXII/Eastern Cooperative Oncology Group (ECOG) 2993 trials. Blood 2007; 109: 3189-3197.

9. Kim M, Yim SH, Cho NS, et al. Homozygous deletion of CDKN2A (p16, p14) and CDKN2B (p15) genes is a poor prognostic factor in adult but not in childhood B-lineage acute lymphoblastic leukemia: a comparative deletion and hypermethylation study. Cancer Genet Cytogenet 2009; 195: 59-65.

10. Lee SD, Lee JH, Min CH. Application of high throughput cell array technology to FISH: Investigation of the role of deletion of P16 gene in leukemias. J Biotechnol 2007; 127: 355-360.

11. Sulong S, Moorman AV, Irving J, et al. A comprehensive analyses of the CDKN2A gene in childhood acute lymphoblastic leukemia reveals genomic deletion, copy number neutral loss of heterozygosity, and association with specific cytogenetic subgroups. Blood 2009; 113: 100-107.

12. Gump J, McGavran L, Wei Q, et al. Analysis of TP53 mutations in relapsed childhood acute lymphoblastic leukemia. J Pediatr Hematol Oncol 2001; 23: 416-419.

13. Kawamura M, Ohnishi H, Guo SX, et al. Alterations of the p53, p21, p16, p15 and RAS genes in childhood T-cell acute lymphoblastic leukemia. Leuk Res 1999; 23: 115-26.

14. Marks DI, Kurz BW, Link MP, et al. High incidence of potential p53 inactivation in poor outcome childhood acute lymphoblastic leukemia at diagnosis. Blood 1996; 87: 1155-1161.

15. Sauerbrey A, Stammler G, Zintl F, et al. Expression of the retinoblastoma tumor suppressor gene (RB-1) in acute leukemia. Leuk Lymphoma 1998; 28: 275-83.

16. Kustanovich AM, Savitskaja TV, Bydanov OI, et al. Aberrant expression of tumor suppressor genes and their association with chimeric oncogenes in pediatric acute lymphoblastic leukemia; Leuk Res 2005; 29: 1271-1276.

17. Schraders M, van Reijmersdal SV, Kamping EJ, et al. High-resolution genomic profiling of pediatric lymphoblastic lymphomas reveals subtle differences with pediatric acute lymphoblastic leukemias in the B-lineage. Cancer Genet Cytogenet 2009; 191: 27-33.

18. Yasar D, Karadogan I, Alanoglu G, et al. Array comparative genomic hybridization analysis of adult acute leukemia patients. Cancer Genet Cytogenet 2010; 97: 122-129.

19. Rand V, Parker H, Russell LJ, et al. Genomic characterization implicates iAMP21 as a likely primary genetic event in childhood B-cell precursor acute lymphoblastic leukemia. Blood 2011; 117: 6848-6855.

20. Hernández JA, Rodríguez AE, González M, et al. A high number of losses in 13q14 chromosome band is associated with a worse outcome and biological differences in patients with B-cell chronic lymphoid leukemia. Haematologica 2009; 94: 364-371.

21. Cheng J, Scilly P, Shew JY, et al. Homozygous deletion of the retinoblastoma gene in an acute lymphoblastic leukemia $(\mathrm{T})$ cell line. Blood 1990; 75: 730-735.

22. Addeo R, Casale F, Caraglia M, et al. Glucocorticoids induce G1 arrest of lymphoblastic cells through retinoblastoma protein $\mathrm{Rb} 1$ dephosphorylation in childhood acute lymphoblastic leukemia in vivo. Cancer Biol Ther 2004; 3: 470-476.

23. Kuper RP, Schoenmakers EF, van Reijmersdal SV, et al. Highresolution genomic profiling of childhood ALL reveals novel recurrent genetic lesions affecting pathways involved in lympho- cyte differentiation and cell cycle progression. Leukemia 2007; 21: 1258-1266.

24. Paulsson K, Cazier JB, Macdougall F, et al. Microdeletions are a general feature of adult and adolescent acute lymphoblastic leukemia: Unexpected similarities with pediatric disease. Proc Natl Acad Sci USA 2008; 105: 6708-6713.

25. Kowalczyk J, Sandberg AA. A possible subgroup of ALL with 9p-. Cancer Genet Cytogenet 1983; 9: 383-385.

26. Andreasson P, Höglund M, Békássy AN, et al. Cytogenetic and FISH studies of a single center consecutive series of 152 childhood acute lymphoblastic leukemias. Eur J Haematol 2000; 65: 40-51.

27. Kees UR, Terry PA, Ford J, et al. Detection of hemizygous deletions in genomic DNA from leukemia specimens for the diagnosis of patients. Leuk Res 2005; 29: 165-171.

28. Carter TL, Terry P, Gottardo N, et al. Deletion of one copy the p16INK4A tumor suppressor gene is implicated as a predisposing factor in pediatric leukemia. Biochem Biophys Res Commun 2004; 318: 852-855.

29. Zuna J, Muzikova K, Hrusak O, et al. Significance of real-time quantitative in childhood acute lymphoblastic leukemia. Haematologica 2002; 87: 668-669.

30. Carter TL, Watt PM, Kumar R, et al. Hemizygous p16INK4A deletion in pediatric acute lymphoblastic leukemia predicts independent risk of relapse. Blood 2001; 97: 572-574.

31. Pastwińska A., Rygier J., Woroniecka B., et al. Frequency of deletion of CDKN2A (9p21) gene in T-cell lymphomas in FISH analysis. Współczesna Onkologia 2011; 15: 131-136.

32. Drexler HG. Review of alterations of the cyclin-dependent kinase inhibitor INK4 family genes p15, p16, p18 and p19 in human leukemia-lymphoma cells. Leukemia 1998; 12: 845-859.

33. Papadhimitriou SI, Polychronopoulou S, Tsakiridou AA, et al. p16 inactivation associated with aggressive clinical course and fatal outcome in TEL/AML1-positive acute lymphoblastic leukemia. J Pediatr Hematol Oncol 2005; 27: 675-677.

34. Lemos JA, Defavery R, Scrideli CA, et al. Analysis of P16 gene mutations and deletions in childhood acute lymphoblastic leukemia. Med J 2003; 121: 58-62.

35. Einsiedel H, Taube T, Hartmann R, et al. Deletion analysis of $\mathrm{p} 16 \mathrm{INKa}$ and $\mathrm{p} 15 \mathrm{INKb}$ in relapsed childhood acute lymphoblastic leukemia. Blood 2002; 99: 4629-4631.

36. Aqirre X, Novo FJ, Calasanz MJ, et al. TP53 is frequently altered by methylation, mutation, and/or deletion in acute lymphoblastic leukemia. Mol Carcinog 2003; 38: 201-208.

37. Vilas-Zornoza A, Agirre X, Martín-Palanco V, et al. Frequent and simultaneous epigenetic inactivation of TP53 pathway genes in acute lymphoblastic leukemia. PLoS One 2011; 6: e17012.

38. Lazaridou A, Miraxtsi C, Korantzis J, et al. Simultaneous detection of BCL-2 protein, trisomy 12 , retinoblastoma and P53 monoallelic gene deletions in B-cell chronic lymphocytic leukemia by fluorescence in situ hybridization (FISH): relation to disease status. Leuk Lymphoma 2000; 36: 503-512.

39. Wattel E, Preudhomme C, Hecquest B, et al. p53 mutations are associated with resistance to chemotherapy and short survival in hematologic malignancies. Blood 1994; 84: 3148-3157.

40. Haferlach C, Dicker F, Herholz H, et al. Mutations of the TP53 gene in acute myeloid leukemia are strongly associated with a complex aberrant karyotype. Leukemia 2008; 22: 1539-1541.

\section{Address for correspondence}

Ewa Studniak PhD

Cytogenetic Unit, Department of Pathology

Pomeranian Medical University

Polabska 4

70-115 Szczecin, Poland

tel./fax +48914661545

e-mail: ewa.studniak@gmail.com 